\title{
Transparência, condução da política monetária e metas para inflação
}

Helder Ferreira de Mendonca Professor do Departamento de Economia da UFF Pesquisador do CNPq

\section{Palauras-chave \\ transparência, política monetária, expectativas, credibilidade.}

Classificação JEL E52, E58.

Key words

transparency, monetary policy, expectations, credibility.

JEL Classification E52, E58.

\section{Resumo}

Dado que o regime de metas para a inflação tem sido adotado por diversos países, e que o principal objetivo dessa estrutura é servir como um guia para as expectativas inflacionárias dos agentes econômicos, a transparência na condução da política monetária tornou-se uma exigência para o bom funcionamento desse regime monetário. Este artigo apresenta um levantamento da evolução observada na pesquisa teórica e empírica sobre a transparência na condução da política monetária. O principal resultado encontrado indica que a transparência deve ser entendida como um mecanismo que, se utilizado de forma correta, pode contribuir para aumentar a credibilidade na condução da política monetária.

\section{Abstract}

Given that several countries have adopted inflation targeting, and that the main objective of this regime is to function as a guide for the inflationary expectations of economic agents, transparency in the handling of the monetary policy becomes a prerequisite for the success of this regime. This paper presents a survey of the evolution in the theoretical and empirical research concerning transparency in handling monetary policy. The main conclusion suggests that transparency must be understood as a mechanism that, if used in correctly, can favor a rise in credibility in the handling of monetary policy. 
[...] there is widespread consensus that the main objective of monetary policy should be price stability, that the central bank (CB) should have the freedom to set the interest rate without political interference, and that the objectives and the procedures followed by the CB should be reasonably transparent (Cukierman, 2002, p. 15).

\section{1_Introdução}

Por volta dos anos 1950, havia a crença de que a política monetária era mais efetiva quanto menos transparente ela fosse. A justificativa para essa visão é que a eficácia da política monetária dependeria da opacidade das ações do Banco Central, uma vez que, dessa forma, seria mais fácil obter os resultados pretendidos com a ação política. Até meados dos anos 1970 , a análise da política monetária tinha como referencial teórico a abordagem keynesiana associada ao trade-off inflação versus desemprego, presente na Curva de Phillips original. ${ }^{1}$ Não obstante, em razão da revolução teórica provocada pela incorporação das expectativas racionais à política econômica e às sucessivas evidências empíricas contrárias ao trade-off mencionado, houve a substituição do paradigma keynesiano na análise teórica da política monetária. O triunfo das expectativas racionais e da taxa natural de de- semprego teve como conseqüência a base do argumento de que a política monetária deve ter como principal objetivo uma inflação baixa e estável.

Ainda nos anos 1970, Kydland e Prescott (1977) deram início ao estudo sobre a credibilidade da política monetária, ressaltando a análise sobre inconsistência temporal. Na perspectiva desses autores, a utilização de regras para a condução da política monetária representa a melhor solução para que a política atual seja consistente com a política de equilíbrio futura. Seguindo a mesma linha de argumentação, Barro e Gordon (1983) retomaram a análise efetuada por Kydland e Prescott e salientaram a importância do papel da reputação como forma de disciplinar a condução da política monetária. O ponto central da análise é que a persistência da inflação é atribuída à perda de reputação do governo graças ao não-cumprimento dos acordos previamente firmados com a sociedade. ${ }^{2} \mathrm{~A}$ partir de então, uma das principais preocupações da literatura passou a ser a busca de uma estrutura para a política monetária capaz de reduzir os estímulos para a autoridade política causar inflação. Em outras palavras, tornou-se necessário o encontro de uma solução para o problema relacionado ao viés inflacionário na condução da política monetária. ${ }^{3}$

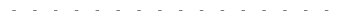

É importante salientar que não se deve atribuir a Keynes a recomendação de falta de transparência para a condução da política monetária. $\mathrm{Na}$ verdade, Keynes foi um defensor da transparência, já que acreditava que, dessa forma, seria mais rápido o alcance dos objetivos planejados pela autoridade política. Para o leitor interessado nessa visão, ver Keynes (1973).

2 Outro importante trabalho para a literatura sobre a conquista de reputação da autoridade monetária representado por um jogo estratégico entre a autoridade monetária e um sindicato é o de Backus e Driffill (1985).

3 O conceito viés inflacionário deriva do argumento de ineficácia das políticas. $\mathrm{O}$ âmago do conceito pode ser entendido como a tentação que os governos sofrem de buscar aumento do produto e/ou redução do nível de desemprego por meio do uso de políticas monetárias expansionistas. 
4 Uma boa interpretação

sobre o critério de

normalidade refere-se ao fato

de que o ponto de partida nas tomadas de decisões acerca de preços, investimento, produção, etc., tem por base o que o agente econômico considera como normal para que sua tomada de decisão seja realizada. Em outras palavras, mudanças em relação ao que os agentes consideram como normal são encaradas como oportunidade de haver uma ação especulativa, ao passo que mudanças permanentes no cenário levariam os agentes a recalcular sua decisão em razão da mudança no próprio padrão de normalidade. Como caso ilustrativo dessa situação, podem-se citar os processos persistentes de alta inflação, em que, por causa das oscilações constantes e imprevistas das taxas de retorno, há um movimento que impede que seja formado um padrão de normalidade.
Hoje em dia, tomando-se como referência os argumentos apresentados por Taylor (1993), tem-se consolidado como objetivo para a política monetária uma taxa de inflação próxima a sua meta e evitar que o produto se desvie do produto potencial. Para a consecução desse objetivo, a taxa de juros de curto prazo tem-se constituído o principal instrumento à disposição da autoridade monetária. A justificativa básica para esse procedimento se deve ao fato de que a inflação e a expectativa de inflação são rígidas, permitindo algum controle do Banco Central sobre a taxa de juros de curto prazo. Dado que a expectativa do público sobre a taxa de juros real de curto prazo futura altera a taxa de juros real de longo prazo, há a possibilidade de alterar os níveis de consumo e investimento, e, por sua vez, a demanda agregada. Ademais, a expectativa de inflação dos agentes econômi$\cos$ e a variação do produto afetam a formação de preços das firmas, e, dessa forma, a inflação.

Quando o Banco Central altera a taxa de juros, as expectativas dos agentes econômicos em relação à evolução presente e futura da economia podem sofrer alterações. Ou seja, um aumento da taxa de juros na tentativa de evitar um aumento da inflação causa efeitos recessivos no curto termo; no entanto, o Banco Central pode restabelecer a confiança no desempenho futuro da economia, fazendo com que as taxas de juros esperadas de médio e longo termo sejam menores. Portanto, é esperado que, no longo termo, o efeito negativo sobre o produto oriundo de um aumento na taxa de juros para evitar um processo inflacionário seja revertido, e que, com a recuperação da normalidade, ${ }^{4}$ seja gerado, no longo termo, um estímulo ao investimento capaz de promover aumento no produto.

Apesar de o Banco Central ter a capacidade de reduzir a taxa de juros real e depreciar a moeda para estimular a atividade econômica, essa postura não pode ser adotada de forma indefinida. No longo prazo, a taxa de juros real de equilíbrio é neutra, isto é, ela é compatível com o produto ao nível potencial. De outra forma, a taxa de juros real de longo prazo é aquela que resulta da ausência de rigidez de preços e outras fricções. Portanto, se o Banco Central insistir em manter uma taxa de juros real abaixo da de equilíbrio por muito tempo, a demanda agregada excede o produto potencial, e, como conseqüência, há uma pressão para que ocorra aumento da inflação na economia. Logo, torna-se justificável o argumento apresentado por Barro (1986) de 
que, no caso da política monetária não estar voltada para o combate à inflação, o processo de desinflação da economia pode implicar sacrifício social maior que o necessário.

Com base na idéia acima, observa-se que a atual preocupação das autoridades monetárias em assegurar a estabilidade de preços fez com que "[...] central bankers' obsession with 'credibility' is completely rational" (Svensson, 2003, p. 12). De maneira geral, a literatura econômica tem destacado a importância da adoção de uma âncora para as variáveis nominais que sirva como guia para as expectativas dos agentes econômicos sobre o comportamento futuro dessas variáveis. Assim, conforme ressaltado por Santomero (2003), o uso da estratégia de metas para a inflação deveria ancorar essas expectativas de forma mais consistente, tornando a estabilidade de preços mais fácil de ser alcançada no longo termo e aumentando a habilidade do Banco Central para estabilizar o produto e o emprego no curto termo.

No período recente, a análise sobre a importância da transparência para a condução da política monetária tem recebido maior atenção dos economistas. De acordo com estudo efetuado por Fry et al. (2000), a partir de uma análise de
1994 de Bancos Centrais, a transparência ocupa o terceiro lugar como variável mais importante para a condução da política monetária. ${ }^{5}$ Dado que há o reconhecimento de que a efetividade da condução da política econômica depende de alguma forma da capacidade do público antecipar as ações do Banco Central; 6 é esperado que a transparência ajude os agentes econômicos a prever melhor as ações da política monetária. Nesse sentido, a transparência contribuiria para o aumento da responsabilidade do Banco Central no alcance das metas anunciadas e, por conseguinte, para o aumento da credibilidade.

Este artigo apresenta um levantamento da evolução observada na pesquisa teórica e empírica sobre a transparência na condução da política monetária. Além desta introdução, o artigo encontra-se estruturado da seguinte forma: na segunda seção são apresentados os fundamentos teóricos para análise sobre transparência com base em uma variação do modelo de Kydland e Prescott (1977); na terceira seção é mostrada a importância da transparência para o regime de metas para inflação; na quarta seção são apresentados os principais argumentos teóricos e empíricos que permeiam a análise sobre transparência da política monetária; por último, são apresentadas as conclusões do artigo.

\footnotetext{
O primeiro lugar é a independência do Banco Central; o segundo lugar, a manutenção de expectativas de baixa inflação.

6 Esta observação é particularmente válida para os mercados financeiros em razão de que erros de informação sobre a política monetária podem gerar flutuações desnecessárias e improdutivas no preço dos diversos ativos.
} 
O conjunto analítico adotado para o caso de regras que apresentam resultado superior ao comportamento discricionário baseia-se em McCallum (1996).

8 Para simplificar a análise, será admitido que os parâmetros $a$ e $b$ são constantes, o que implica que $\Delta M_{t}$ passa a ser um valor constante.

\section{2_ A fundamentação teórica para a transparência}

A antiga literatura sobre regras versus discricionariedade focava as intenções e a capacidade do responsável pela política. Os argumentos favoráveis ao uso de regras levavam em conta o conhecimento imperfeito sobre a economia e a tendência da política monetária ser conduzida de forma inadequada do ponto de vista do bem-estar social. Tomando-se por base o trabalho de Kydland e Prescott (1977), essa perspectiva foi alterada, de forma que as regras passaram a ser utilizadas como um compromisso para a autoridade política.

O principal argumento teórico para o aumento da transparência na condução da política monetária pode ser mais bem compreendido por meio de uma variação no modelo padrão da análise regras versus discrição. ${ }^{7}$ Para tanto, assume-se que a autoridade monetária tem como objetivos uma taxa de inflação próxima a zero e uma taxa de desemprego baixa. Ademais, é admitido que a inflação é determinada, em grande medida, pela taxa de crescimento monetário, e que o nível de desemprego está relacionado com a taxa não-esperada de aumento da oferta de moeda. Dessa forma, pode-se expressar os objetivos do Banco Central em termos da variação monetária $\left(\Delta M_{t}\right)$ e da surpresa na expansão monetária $\left(\Delta M_{t}-\Delta M_{t}^{e}\right)$. Portanto, o objetivo da autoridade monetária para o instante $t$ consiste em minimizar o valor de

$L_{t}=\frac{a}{2} \Delta M_{t}^{2}-b\left(\Delta M_{t}-\Delta M_{t}^{e}\right)$

onde $a$ e $b>0$

Admitindo-se a hipótese de que o público possui expectativas racionais para a variação da oferta de moeda, isso implica que $\Delta M_{t}^{e}=E_{t-1} \Delta M_{t}$, ou seja, na média os agentes acertam suas expectativas em relação à $\Delta M_{t}$.

A questão relevante passa a ser qual o valor de $\Delta M_{t}$ da equação (1) sob o caso de regras e de discrição. ${ }^{8}$ Se a autoridade monetária decide obter o melhor valor de $\Delta M_{t}$ para um grande número de períodos, ou seja, deseja adotar uma regra não ativista e as expectativas são racionais (na média $\Delta M_{t}^{e}=\Delta M_{t}$ ), o problema passa a ser a obtenção do valor de $\Delta M_{t}$ que minimiza

$L_{t}=\frac{a}{2} \Delta M_{t}^{2}$, isto é,

$\frac{\partial L_{t}}{\partial M_{t}} a \Delta M_{t} \therefore$

$\Delta M_{t}=0, \forall t \Rightarrow L_{t}=0$ 
Ou seja, para o caso de um comportamento com base em regras, o melhor resultado possível seria oriundo do compromisso de o Banco Central não fazer uso de expansão monetária.

Por outro lado, se for adotado um comportamento discricionário, isso implica que as escolhas são feitas período a período. Nesse caso, a autoridade monetária pode fazer a escolha de $\Delta M_{t}$ para qualquer ponto no tempo. Considerando a situação em que o Banco Central procura definir a melhor variação monetária, por exemplo, para o instante 3 , o objetivo passa a ser a escolha de $\Delta M_{3}$ que minimiza o valor de

$L_{3}=\frac{a}{2} \Delta M_{3}^{2}-b\left(\Delta M_{3}-\Delta M_{3}^{e}\right)$

Em relação ao caso anterior, a diferença consiste no fato de que $\Delta M_{3}^{e}$ foi determinado no final do período 2 . Portanto, para a autoridade monetária, $\Delta M_{3}^{e}$ é um número conhecido, e por conseguinte, há a possibilidade do segundo termo da equação (2) ser diferente de zero.

O valor de $\Delta M_{3}^{e}$ que minimiza (2) é obtido por meio de

$\frac{\partial L_{3}}{\partial M_{3}} a \Delta M_{3}-b \Rightarrow \Delta M_{3}=\frac{b}{a}$

Sob discrição, esse resultado é válido apenas para o período 3. Se o Banco
Central desejar obter o melhor resultado de $\Delta M_{t}$ para o período 4 , a função objetivo que deverá minimizar corresponde a

$L_{4}=\frac{a}{2} \Delta M_{4}^{2}-b\left(\Delta M_{4}-\Delta M_{4}^{e}\right) \Rightarrow \Delta M_{4}=\frac{b}{a}$

Repetindo-se esse procedimento, verifica-se que, independentemente do período que se estiver considerando na análise, a melhor escolha para a autoridade monetária será dada por

$\Delta M_{t}=\frac{b}{a}, \forall t \Rightarrow \Delta M_{t}^{e}=\frac{b}{a}$

Fazendo-se a substituição desse resultado na equação (1), obtém-se,

$L_{t}=\frac{b^{2}}{2 a}$

Portanto, a perda resultante do comportamento discricionário da autoridade monetária é maior do que onde há adoção de regras $\left(L_{\text {regras }}=0<L_{\text {discric. }}=b^{2} / 2 a\right)$.

$\mathrm{O}$ modelo apresentado não pode ser entendido como um resultado definitivo. Na maioria dos modelos que tratam o assunto, a variável choque inserida na análise corresponde a um termo sem correlação serial e com média tendendo a zero. Em outras palavras, os resultados de um choque sobre a economia são negligenciáveis. Assim, admitindo-se que a política monetária não determina de forma 
perfeita a inflação e o desemprego, é preciso acrescentar à equação (1) um termo referente aos efeitos indesejados (perda não prevista pelo Banco Central) que uma variação monetária causa sobre os objetivos supracitados $\left(a b \Delta \xi_{t}\right)$. Ou seja, a equação (1) pode ser reescrita como

$L_{t}=\frac{a}{2} \Delta M_{t}^{2}-b\left(\Delta M_{t}-\Delta M_{t}^{e}\right)+a b \Delta \xi_{t}$

Deve-se ressaltar que o termo $a b \Delta \xi_{t}$ presente na equação (6) não implica mudança para a determinação do melhor resultado da variação monetária no caso de regras. ${ }^{9}$ Há uma diferença, porém, em relação ao caso anterior. O resultado da minimização de $L_{t}$ pode ser diferente de zero, visto que

$L_{t}=a b \Delta \xi_{t}$

Portanto, o resultado de (7) depende da magnitude do choque sobre a economia.

No caso de comportamento discricionário, é permitido o uso da política econômica em resposta aos choques. Assim, considerando que se está admitindo que a variação na oferta de moeda é a responsável pela produção dos choques sobre a economia, a função de perda social dada pela equação (6) pode ser reescrita para o caso discricionário como equivalente a
$L_{t}=\frac{a}{2} \Delta M_{t}^{2}-b\left(\Delta M_{t}-\Delta M_{t}^{e}\right)+a b \Delta M_{t}$

Logo, a menor perda que a autoridade monetária pode obter é dada por $\frac{\partial L_{t}}{\partial M_{t}} a \Delta M_{t}-b+a b$

$\Rightarrow \Delta M_{t}=\frac{b(1-a)}{a}$

$\because L_{t}=\frac{b^{2}\left(1-a^{2}\right)}{a}$

Esse resultado traz implicações importantes, uma vez que, se $a$ for igual a 1 , se encontra um valor para $L_{t}$ que corresponde a zero. Em outras palavras, no caso de haver um esforço adequado do responsável pela política monetária no combate à inflação $(a=1)$, é possível obter melhor resultado para a função objetivo $\left(L_{t}=0\right)$.

Com base no que foi apresentado, obtém-se o seguinte corolário - na ausência de choques sobre a economia, o comportamento associado a regras apresenta resultados superiores ao comportamento discricionário. Por outro lado, quando é removida a hipótese de que o Banco Central tem controle perfeito sobre a inflação, o comportamento discricionário, associado ao esforço adequado do responsável pela política monetária no controle da inflação, apresenta resultado superior. 
$\mathrm{Na}$ busca de mecanismos que induzam a autoridade monetária ao comportamento ideal para o combate à inflação (eliminar o viés inflacionário na condução da política monetária), a literatura tem apresentado três soluções básicas:

i. o Banco Central poderia abandonar a discrição e seguir uma regra política - proposta originalmente apresentada por Kydland e Prescott (1977). Conforme pode ser observado pelo resultado do modelo acima, essa solução é satisfatória para o caso de inexistência de choques sobre a economia.

ii. o público poderia escolher um presidente do Banco Central conservador - Rogoff (1985) sugeriu a adoção de um Banco Central independente com um presidente conservador (aversão à inflação maior do que a da média da sociedade) para inibir a manifestação do viés inflacionário. Lohmann (1992), explorando o trade-off comprometimento e flexibilidade, verificou que, na presença de choques de oferta e de conflito entre a autoridade monetária e a fiscal, seria adequada a escolha de um presidente do Banco Central conservador para Bancos Centrais parcialmente independentes. iii. o Banco Central poderia ser limitado por contratos de incentivo - de acordo com Walsh (1995), o problema do viés inflacionário é resolvido pela estruturação de um contrato que impõe custos ao Banco Central quando a inflação se desvia do nível ótimo. Em outras palavras, sob essa concepção, o principal (governo) assina um contrato de incentivo com um agente (Banco Central), segundo o qual o agente fica sujeito ao conjunto de penalidades $e x$ post, que será determinado pelo desvio da inflação à meta preestabelecida. A vantagem dessa estrutura advém do fato de que o melhor resultado para a sociedade é obtido, independentemente de o governo e o Banco Central partilharem da mesma função, do mesmo objetivo e do mesmo conjunto de informações. No modelo de Svensson (1997), um regime de meta de inflação é interpretado como um arranjo do agente e o principal, em que a sociedade (o principal) delega a política monetária ao Banco Central (o agente). Outrossim, é assumido que o Banco Central tem controle perfeito sobre a inflação. $\mathrm{O}$ resultado encontrado indica 

10 A independência de meta refere-se à liberdade que o Banco Central tem para definir qual o objetivo a ser alcançado (Fischer, 1995).

11 É importante ressaltar que, embora a literatura apresente estreita relação entre a independência do Banco Central e o regime de metas de inflação, não é necessária a presença de um Banco Central independente para a implementação do regime monetário em questão. que pode ser obtido um equilíbrio que corresponda a uma regra ótima sob compromisso.

O terceiro ponto acima está associado à propagação do uso da estratégia de metas para a inflação. Ademais, observa-se que, para o sucesso no combate à inflação, a independência de meta para o Banco Central não é essencial. ${ }^{10}$ Essa observação está relacionada à validade da hipótese da neutralidade da moeda, isto é, no longo prazo, a política monetária seria incapaz de afetar variáveis reais da economia (produto, emprego, taxa de câmbio real, etc.). Logo, a busca pela estabilidade de preços seria uma meta natural para a autoridade monetária. Assim sendo, seria preciso desenvolver mecanismos que assegurassem ao Banco Central os instrumentos necessários para a obtenção de sua meta natural sem depender de nenhuma outra autoridade política. Em outras palavras, seria necessário o desenvolvimento da independência de instrumento do Banco Central. ${ }^{11}$

Conforme identificado por Herrendorf (1998), há estreita relação entre regime de metas para a inflação, independência de instrumento e transparência na condução da política monetária.

[The] inflation targeting arrangement that gives instrument independence to the cen- tral bank reduces the inflationary bias of monetary policy making. The reason for this result is that if the inflation target is publicly announced the arrangement is transparent, solves the private information problem and makes reputation more effective (Herrendorf, 1998, p. 443).

Portanto, uma explicação para a necessidade da transparência da política monetária é que ela serve como complemento para a independência do Banco Central. Sob essa visão, algum grau de transparência é necessário para garantir a responsabilidade na condução da política monetária e para salvaguardar a legitimidade democrática de Bancos Centrais independentes. Assim, a transparência do Banco Central torna-se indispensável para reduzir o nível de incerteza na economia, uma vez que ela atenuaria a existência de informação assimétrica entre os responsáveis pela política monetária e outros agentes econômicos.

\section{3_ Metas para inflação e transparência}

É reconhecido que o sucesso de uma política antiinflacionária depende do nível de confiança que os agentes econômicos depositam na exeqüibilidade de a política anunciada ser implementada e ser cumprida até o fim. Logo, a presença da in- 
certeza na economia torna-se importante elemento para reduzir a credibilidade. No período atual há duas fontes potenciais de incerteza na economia (Heron, 2003), a saber:

i. eventos inesperados - choques (externos e internos) sobre a economia e erros de previsão para a política monetária;

ii. os agentes econômicos não compreendem, de forma clara, quais são os objetivos de longo prazo para a política monetária.

Com o objetivo de atenuar a fonte de incerteza destacada no segundo ponto, o regime de metas para a inflação tem ganhado atenção de diversos países desde os anos 1990.

$\mathrm{Na}$ análise sobre o regime de metas para a inflação, a credibilidade do regime é resultado de dois tipos de credibilidade (Andersson; Berg, 1995), quais sejam:

i. credibilidade operacional - referese à habilidade de o Banco Central fazer uso da política monetária, de forma que a meta de inflação anunciada seja cumprida;

ii. credibilidade política - reflete o temor dos investidores em relação à probabilidade do regime monetário mudar e, por conseguinte, a busca da estabilidade de preços deixar de ser prioridade para a condução da política monetária. ${ }^{12}$

A estratégia mais utilizada para a implementação do regime de metas para a inflação tem sido o anúncio de bandas. Uma banda mais larga implica maior flexibilidade e maior probabilidade de a meta ser alcançada. Todavia, o uso de uma banda mais larga prejudica a formação de expectativas dos agentes econômicos. No caso de haver falta de credibilidade, o público incorpora às expectativas o limite superior da banda, o que resulta em mais tempo para alcançar a estabilidade de preços. Portanto, se o anúncio de uma meta para a inflação não é crível, torna-se necessário um substancial efeito adverso sobre o produto e o emprego no curto prazo, para tornar efetiva a expectativa de queda da inflação pelo público. Não obstante, o benefício que pode ser obtido pelo anúncio de uma meta inflacionária explícita é que, se ela for crível, pode induzir os agentes a refazer suas expectativas, fazendo com que elas convirjam, de forma rápida, para a meta anunciada. ${ }^{13}$

Outra possibilidade para a implementação da estratégia de metas para a inflação é o anúncio de uma meta que tem como base um único número com a presença de cláusulas de escape. ${ }^{14}$ Deve-se ressaltar que, no caso de os agentes serem dotados de expectativas racionais, 12 É importante salientar que a credibilidade política depende muito mais do suporte político para a busca da estabilidade de preços do que propriamente da condução da política monetária para esse fim.

13 Apesar do argumento de que metas inflacionárias são capazes de aumentar a transparência e reduzir o viés inflacionário da política monetária, deve-se lembrar que o regime sobredito permite a ação discricionária do Banco Central, o que, por sua vez, não elimina por completo o viés inflacionário (Herrendorf, 1998). Portanto, o uso desse regime por si só não significa que o Banco

Central seja sempre avesso à inflação.

14 Em geral, as cláusulas de escape têm sido utilizadas para excluir os efeitos decorrentes de importantes choques de oferta, tais como: mudanças nos termos do comércio; mudanças nos impostos indiretos; desastres naturais; encargos governamentais; e taxas de juros. 


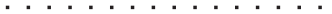

$15 \mathrm{O}$ caso mais formalizado para a transparência das ações do Banco Central é o da Nova Zelândia. Nesse país, o governo tem o direito de demitir o presidente do Banco Central, caso a inflação se desvie em $25 \%$ da taxa anunciada. Exemplo de benefícios oriundos de maior transparência das ações do Banco Central podem ser ilustradas com os casos do Canadá e da Inglaterra. Para uma análise detalhada sobre esses países, ver Mishkin e Posen (1997).

16 Agradeço a um parecerista pela observação que deu origem a este parágrafo. a utilização de uma banda ou de um único ponto como meta não tem grande relevância. A justificativa para essa observação se deve ao fato de que os agentes econômicos reconhecem que as autoridades monetárias não possuem controle perfeito sobre a taxa de inflação. Logo, mesmo que seja anunciado um ponto como meta, as expectativas serão formadas para uma taxa de inflação próxima àquela anunciada. A principal vantagem para a utilização de bandas é que a transparência é maior, e pequenas flutuações na taxa de inflação não precisam ser justificadas à população (Brunilla e Lahdenperä, 1995).

A necessidade do aumento da transparência na condução da política monetária tem-se constituído um dos principais argumentos favoráveis à adoção de metas inflacionárias. ${ }^{15} \mathrm{Na}$ maioria dos países que utilizam o sistema de metas para a inflação, a transparência torna-se maior em razão do anúncio de uma meta explícita para a inflação e do aumento da comunicação entre a autoridade monetária e o público.

Uma importante observação sobre a relação entre comunicação e transparência é feita por Bernanke (2004). Esse autor contrasta políticas como regras de Taylor que se baseiam em regras de feedback com políticas como as associadas com o regime de metas inflacioná- rias que se baseiam em previsões. O resultado obtido indica que a importância da comunicação e da transparência é muito maior no segundo grupo de políticas graças à necessidade que a inferência do público sobre o curso provável de ação do governo tem nesses ambientes. ${ }^{16}$

Em geral, o aumento da comunicação da autoridade monetária com o público é feito por meio de relatórios de inflação, que apresentam quatro pontos básicos (Mishkin, 1999):

i. as metas e os limites da política monetária;

ii. os valores numéricos da meta de inflação e como eles foram determinados;

iii. de que forma as metas para a inflação serão obtidas, dadas as condições atuais da economia;

iv. as razões para os possíveis desvios em relação às metas anunciadas.

Conforme ressaltado por Svensson (1999), um aumento na transparência é importante para que se torne eficiente a estrutura de delegação da responsabilidade da condução da política monetária em uma sociedade democrática. O esquema a seguir elucida essa afirmação:

i. a sociedade, por meio do governo (seu representante direto), anuncia a meta para a política monetária; 
ii. o Banco Central tem independência operacional para perseguir a meta sem interferência de natureza política;

iii. o Banco Central é responsável pela obtenção das metas.

Assim, a transparência tem papel relevante para que o público compreenda o funcionamento da política monetária, e, como conseqüência, aumente a velocidade de convergência de suas expectativas para as metas anunciadas.

A transparência também teria efeito disciplinador, uma vez que o aumento da probabilidade de o público perceber um desvio da condução da política monetária em relação às metas estabelecidas provocaria um custo mais elevado para o Banco Central descumprir as metas (perda de credibilidade). Dessa forma, maior transparência contribuiria para aumentar o compromisso da autoridade monetária na consecução das metas anunciadas. Em outras palavras, a transparência funciona como mecanismo de comprometimento do Banco Central com a meta de inflação.

Em suma, a importância da transparência para o regime de metas para inflação se deve ao fato de que o equilíbrio ótimo para essa estratégia depende do quão são garantidos a responsabilidade e o monitoramento da condução da po- lítica monetária. Se o Banco Central tem pouca informação sobre os choques inflacionários, ou se a política é transparente de forma que o público consegue verificar a informação do Banco Central, maior peso é dado ao alcance da meta de inflação (Walsh, 2003).

\section{4_A literatura sobre transparência}

A idéia de que a transparência na condução da política monetária é benéfica para a economia tem os seguintes pontos como premissas:

i. redução de incerteza - conseqüência do fato de que a transparência da política monetária foca a estabilidade de preços, contribuindo para a obtenção de menor inflação média e maior estabilidade financeira;

ii. aumento da responsabilidade na condução da política monetária - a transparência serve como proteção para a política monetária diante das pressões de natureza política.

Uma indicação da importância da transparência na condução da política econômica está presente no código de boas práticas para as políticas monetária e fiscal do Fundo Monetário Internacional (parágrafo 4): 
$\ldots \ldots \ldots$

17 Neste caso, observa-se, como mecanismos capazes de aumentar a transparência, o uso de metas explícitas de inflação; a independência do Banco Central; e o uso de contratos.
The case for transparency of monetary and financial policies is based on two main premises. First, the effectiveness of monetary and financial policies can be strengthened if goals and instruments of policy are known to the public and if authorities can make a credible commitment to meeting them. In making available more information about monetary and financial policies, good transparency policies promote the potential efficiency of markets. Second, good governance calls for central banks and financial agencies to be accountable, particularly where the monetary and financial authorities are granted a high degree of autonomy.

De acordo com Geraats (2002), há cinco formas diferentes de transparência:

i. transparência política - refere-se à acessibilidade do público em relação aos objetivos políticos e aos arranjos institucionais que clarificam a conduta dos responsáveis pela política; ${ }^{17}$

ii. transparência econômica - referese à informação econômica (dados, modelos políticos, e previsões do Banco Central), que é utilizada para a condução da política monetária;

iii. transparência de procedimento descreve a forma como as decisões da política monetária são tomadas (estratégia e responsabilidade);

iv. transparência de política - diz respeito ao anúncio das decisões políticas, concomitantemente, a sua explicação e uma indicação da tendência para as ações políticas futuras;

v. transparência operacional - refere-se à implementação da política monetária, incluindo uma discussão sobre o controle de erros para o uso de instrumentos e os mecanismos de transmissão.

Com base nos pontos acima, observa-se que a transparência poderia promover o aumento na responsabilidade da condução da política monetária de diversas maneiras. A transparência política (na forma de objetivos formais, metas quantitativas, e clareza sobre a estrutura institucional) oferece um critério para o público avaliar e identificar quem é o responsável pela obtenção das metas anunciadas. Ademais, as transparências: econômica, de procedimento, e de política; estão relacionadas a um aumento da responsabilidade de forma ex ante, já que permitem examinar as motivações para as ações políticas. Em relação à transparência operacional, observa-se que há uma contribuição ex post para a responsabili- 
dade, uma vez que ela possibilita aos agentes econômicos fazerem uma avaliação dos resultados da política implementada.

$\mathrm{Na}$ maior parte da literatura, a definição de transparência corresponde, de forma implícita, à informação simétrica e é modelada como o grau de informação assimétrica sobre erros de controle ou choques econômicos sobre instrumentos políticos. Conforme destacado por Geraats (2002), existem dois efeitos que estão relacionados à análise sobre transparência:

i. efeito incerteza - a informação assimétrica gera incerteza para os agentes econômicos que precisam aprender por experiência própria, e permite a oportunidade para outros explorarem a presença de informação privada;

ii. efeito incentivo - os agentes econômicos que possuem acesso à informação privada podem tentar influenciar o comportamento dos demais por meio da divulgação de informações.

Partindo-se do pressuposto de que a transparência é capaz de remover a informação assimétrica dos agentes econômicos, é possível fazer uma associação com o primeiro teorema do bem-estar. ${ }^{18}$ Logo, um aumento na transparência de- veria incrementar o bem-estar, visto que haveria redução nos erros de previsão e na variabilidade esperada das variáveis sujeitas à incerteza.

Faust e Svensson (2001) mostram que um elevado grau de transparência da política monetária contribui para a melhora do bem-estar social. De acordo com a análise apresentada por esses autores, o aumento da transparência causa redução no viés inflacionário, na variabilidade da inflação e na variabilidade do emprego. Esse resultado é obtido fazendo uso de uma variação no modelo de Barro e Gordon (1983), em que é considerado que o Banco Central não anuncia a meta de emprego e que essa varia ao longo do tempo de acordo com um componente idiossincrático. Assim, flutuações nesse componente da meta do emprego tenderiam a fazer com que o Banco Central se desviasse da meta de inflação anunciada. Admitindo-se que não há o controle perfeito da inflação, e que o comportamento dessa variável depende das intenções do Banco Central e do seu erro de controle, a autoridade monetária decide qual a extensão do erro de controle sobre a inflação que será revelada ao público. Com base nessa estrutura, o Banco Central transmite aos agentes econômicos sua intenção para a inflação, e portanto, permite-lhes inferir qual é a 18 De acordo com o primeiro teorema do bem-estar, uma alocação de equilíbrio obtida por meio de um conjunto de mercados competitivos é eficiente de Pareto. 
meta de emprego. Nesse sentido, o aumento da transparência seria desejável, já que faria com que o Banco Central revelasse maior proporção do componente observável do controle de erro, e, por conseguinte, melhoraria a capacidade de o público deduzir a meta de emprego.

De forma analítica, Faust e Svensson (2001) distinguem três diferentes regimes:

i. transparência mínima - nem o objetivo referente ao emprego nem as intenções do Banco Central são observáveis pelo público;

ii. elevado grau de transparência permite que o público observe as intenções do Banco Central em relação à inflação. Como conseqüência, há obtenção de uma inflação mais baixa para a economia, uma vez que a sensibilidade da reputação dos Bancos Centrais às suas ações aumenta, tornando-se mais custoso para a autoridade monetária buscar uma política de inflação elevada;

iii. transparência extrema - tanto a meta de emprego quanto às intenções do Banco Central são observadas pela sociedade.

Nesse caso, as ações do Banco Central não representam informação adicional sobre o viés inflacionário nem afetam a sua reputação.
De forma análoga à estrutura informacional adotada pelos autores sobreditos, mas adotando um modelo com elementos novos-keynesianos (contratos sobrepostos e concorrência monopolista), Jensen (2000) verifica que o aumento da transparência ocasiona aumento da credibilidade. A principal justificativa para esse resultado é que maior transparência incrementa o custo do Banco Central em virtude da perda de reputação decorrente dos desvios em relação à meta de inflação. Todavia, o modelo de Jensen revela que, quando as preferências da autoridade monetária são de conhecimento do público, o efeito da maior transparência sobre a credibilidade é redundante. Ademais, a transparência torna-se uma severa limitação para o Banco Central responder a choques sobre a economia. Logo, a escolha do grau ótimo de transparência relaciona-se com o trade-off entre flexibilidade e credibilidade. Sob essa perspectiva, um elevado grau de transparência é desejável para Bancos Centrais com baixa credibilidade, mas é altamente custoso para aqueles com alta credibilidade.

Ainda em relação à questão sobre o quão desejável seria a transparência, Mishkin (2004) ressalta que transparência deve ser um meio, e não um fim. Nesse sentido, a transparência é benéfica quando ela simplifica a comunicação com o 
público e ajuda a criar um suporte para Bancos Centrais conduzirem a política monetária de forma ótima para os objetivos de longo prazo. Todavia, conforme ressaltado pelo mesmo autor, o anúncio da função objetivo do Banco Central ou das projeções da trajetória da política de juros não se constitui um tipo de transparência desejável, já que essa não está associada aos benefícios supracitados.

Além da análise do efeito da transparência sobre a reputação, outra parte da literatura concentra-se em avaliar as conseqüências da divulgação das informações do Banco Central sobre os choques estocásticos. Tomando como referência o modelo de Barro e Gordon (1983) e adotando um único período para análise, Cukierman (2000) verifica o impacto da informação privada do Banco Central na iminência de um choque. No caso de transparência limitada, o Banco Central revela sua preferência depois de o público fazer suas previsões sobre o choque. Por outro lado, no caso de haver total transparência, a preferência é revelada antes de o público formar suas expectativas.

O resultado encontrado por Cukierman (2000) é que, em um ambiente neoclássico, os diferentes graus de transparência afetam apenas a variabilidade da inflação, e não o seu nível médio. Esse re- sultado se deve ao fato de o público estar atento aos choques de oferta, e, portanto, o Banco Central perde sua vantagem informacional, e não pode criar uma surpresa inflacionária para estabilizar a economia. Com base nessa interpretação, o bem-estar social esperado é sempre maior sob um regime de transparência limitada do que no caso de total transparência. No caso de total transparência (tanto sob previsão perfeita e imperfeita do Banco Central), a inflação esperada é sempre zero e, por conseguinte, o Banco Central não pode afetar o emprego. Em relação ao caso de um modelo neokeynesiano, é observado que a sociedade é indiferente aos dois regimes de transparência (limitada e total), desde que a taxa de juros não seja incluída na função de perda. Entrementes, no caso da variabilidade de a taxa de juros ser incluída na função de perda, o regime de transparência limitada tornase superior ao de transparência total.

Geraats (2001), também fazendo uso de uma variação do modelo de Barro e Gordon (1983), realiza outra análise para transparência, concentrando-se na publicação das previsões do Banco Central. Nesse modelo são considerados dois períodos para análise, e a taxa de juros real é utilizada como mecanismo de transmissão. Ademais, o Banco Central tem infor- 
$\because \cdots \cdots \cdot \cdots \cdot \cdots \cdot \cdots \cdot \cdots$ 19 A expressão "forte" está associada à idéia de que há comprometimento efetivo no combate à inflação, ao passo que "fraco" significa que a busca pela estabilidade de preços não é prioritária. mação privilegiada sobre os choques de oferta e demanda, e não publica as metas para a inflação.

Assim, maior transparência permite ao público observar os choques de oferta e demanda do primeiro período efazer inferências sobre a meta de inflação do Banco Central. Portanto, maior transparência torna a reputação do Banco Central mais sensível à suas ações. Logo, uma política monetária opaca é caracterizada por uma inflação mais elevada no primeiro período. A justificativa para esse resultado é que a não-publicação das previsões do Banco Central implica uma perda de reputação. Graças à incerteza do tipo do Banco Central (forte ou fraco ${ }^{19} \mathrm{em}$ relação a sua aversão à inflação, o público tende a interpretar que a nãopublicação é um indicativo de que o Banco Central é "fraco". O principal resultado obtido é que a transparência reduz a variabilidade da inflação, mas o efeito sobre o produto é ambíguo.

Um elemento comum na literatura dos modelos sobre transparência é que ela faz com que a reputação seja mais dependente das ações da autoridade monetária, e, como conseqüência, há um desestímulo para fazer uso de políticas inflacionárias. Entretanto, é importante reconhecer que a transparência tem menor efeito sobre a reputação quando as preferências do Banco Central são conhecidas pelo público. Portanto, para que alguma forma de transparência seja relevante, é preciso que exista alguma assimetria de informação na política monetária. Outro ponto a ser realçado é que a transparência contribui para disciplinar a inflação em razão da restrição imposta ao Banco Central para estabilizar a economia por meio de um choque de demanda agregada.

\section{1_Evidências empíricas sobre transparência}

A literatura teórica sobre transparência identifica diversos canais de como o aumento da transparência pode afetar os resultados da política econômica. Conforme apontado por Chortareas, Stasavage e Sterne (2002), não há um conceito de transparência universalmente aceito. Diversos autores conceituam transparência em direções distintas, levando em conta: preferências, modelos, conhecimento de choques que incidem sobre a economia, ou a implementação de decisões políticas. Como a análise sobre a transparência da política monetária ainda é muito recente, há poucos estudos empíricos que servem para avaliar as asserções teóricas. Assim, não há característica comum para essa literatura, e os resultados obtidos 
são preliminares. Com o objetivo de apresentar um panorama dos estudos realizados, é relatada, a seguir, uma síntese de diversos trabalhos.

Cecchetti e Krause (2002) analisam de que forma medidas de independência do Banco Central - responsabilidade, transparência e credibilidade - estão relacionadas à inflação média (amostra de 63 países), ao desempenho macroeconômico e à ineficiência política (amostra de 24 países). Os resultados obtidos indicam que a média da inflação encontra-se inversamente relacionada às medidas das variáveis mencionadas. Por outro lado, os resultados não se mostram satisfatórios quando o desempenho macroeconômico e a ineficiência política são considerados. Além de a maioria das relações estatísticas mostrarem-se insignificantes, alguns sinais revelam-se contrários ao que é esperado pela teoria econômica. Entre os resultados encontrados nessa direção, observa-se que a independência do Banco Central e a responsabilidade tendem a reduzir a efetividade da política. Ademais, apesar de as medidas de transparência e de credibilidade apresentarem os sinais de acordo com o esperado, apenas o índice de credibilidade é estatisticamente significativo.

Chortareas, Stasavage e Sterne (2002) avaliam o efeito da transparência sobre a inflação e a volatilidade do produto. Para tanto, é elaborado um índice de transparência da autoridade monetária sobre suas previsões com base em quatro questões:

i. se as previsões são publicadas;

ii. se as previsões são forward looking; iii. se há uma discussão dos erros de previsão cometidos no passado; iv. se há alguma indicação dos riscos associados com as previsões.

Utilizando esse índice de transparência, é feita uma análise de corte transversal, considerando uma amostra de 87 países entre o índice obtido e a média da taxa de inflação para o período 1995-1999. ${ }^{20}$ O resultado encontrado indica que há relação estatisticamente significativa entre essa medida de transparência e a inflação e, portanto, países que são mais transparentes quanto às suas previsões têm menores taxas de inflação. Ademais, não foram encontradas evidências de que maior transparência esteja associada a maior volatilidade do produto.

Outro ponto que é alvo da análise empírica sobre transparência diz respeito à importância do aumento da comunicação, por meio de relatórios de inflação, para a condução da política monetária. Nessa perspectiva, Fracasso, Genberg e Wyplosz (2003) analisaram os relatórios A análise também é feita para outras variáveis: PNB per capita, uma medida de abertura da economia, uma medida de instabilidade política, e uma variável dummy. 
de inflação produzidos por 29 Bancos Centrais que fazem uso do regime de metas para inflação. Com o objetivo de avaliar se a previsibilidade da política monetária é relacionada com a qualidade dos relatórios de inflação, os autores mencionados realizaram uma análise cross-country. Para tanto, foi construída uma medida de surpresa no movimento das taxas de juros que está associada às reuniões dos Comitês de Política Monetária. Os resultados obtidos sugerem que um relatório de inflação de boa qualidade contribui para o melhor entendimento das decisões de política monetária.

Bernanke, Reinhart e Sack (2004) analisaram se a comunicação do comitê de política monetária é capaz de guiar as expectativas do público em relação ao curso futuro das taxas de juros, o que, por conseguinte, denotaria maior capacidade de o comitê influenciar a taxa de juros de longo prazo e o alcance dos objetivos macroeconômicos. O resultado obtido indica que, no caso do Federal Open Market Committee, as informações divulgadas pelo comitê representam ferramenta poderosa para afetar as expectativas de mercado sobre o curso futuro da taxa de juros básica da economia.

\section{5_Uma breve reflexão sobre o caso brasileiro}

Desde a introdução do regime de metas para inflação na economia brasileira em junho de 1999, o debate sobre a transparência da condução da política monetária tornou-se relevante.

In particular, inflation targeting was seen as providing a nominal anchor both for monetary policy and inflation expectations, making this anchor identical to the long-run objective of monetary policy; providing more transparency and accountability to the design and implementation of monetary policy; facilitating its communication, understanding, and assessment; and providing effective policy guidance by focusing policymakers' attention on the longrun consequences of short-term policy actions (IMF, 1999).

$\mathrm{Na}$ percepção de Mishkin e Schmidt-Hebbel (2001), o Brasil fez a opção de adotar um regime pleno de metas para inflação desde a sua introdução. Sendo assim, são características do caso brasileiro: ausência de outra âncora nominal, compromisso institucional com a estabilidade de preços, ausência de dominância fiscal, independência de instrumento (operacional) da autoridade monetária, política de transparência e responsabilidade. 
O fato de o Banco Central do Brasil (BCB) preocupar-se em revelar que a estabilidade de preços é o objetivo prioritário, assim como a diretriz para o comportamento da taxa de câmbio e da taxa de juros, denota claro aumento na transparência das ações da autoridade monetária. Conforme Bogdanski, Tombini e Werlang (2001), a comunicação efetiva das ações do BCB tornou-se fundamental para que o público pudesse compreender e monitorar as decisões da autridade monetária. Além disso, permitiu que os cidadãos entendessem os motivos para os desvios em relação à meta de inflação anunciada.

Com o objetivo de incrementar a comunicação do BCB com os agentes econômicos, depois da adoção do regime de metas para inflação, relatórios trimestrais de inflação passaram a ser divulgados. De acordo com levantamento efetuado por Fracasso, Genberg e Wyplosz (2003), considerando uma amostra de 20 países que divulgam relatórios de inflação, o Brasil aparece na terceira posição, atrás apenas do Reino Unido e da Nova Zelândia. Essa é uma informação valiosa, já que revela a preocupação do BCB de divulgar informações com qualidade sobre a condução da política monetária.

Mishkin (2004) destaca que o Brasil publica projeções da trajetória futura da política de taxa de juros com base nas expectativas de mercado. De acordo com a visão desse autor, esse tipo de informação é relevante principalmente para o caso de economias emergentes. A justificativa é que, na maioria das vezes, os Bancos Centrais dessas economias têm baixa credibilidade. Logo, torna-se necessária a publicação de previsões, de forma que aumente o nível de informação do público, mesmo que tais previsões não se baseiem em estimações do Banco Central.

Levando em conta a classificação feita por Geraats (2002 - vide seção 4), as oito principais medidas adotadas pelo $\mathrm{BCB}$, durante o processo de adoção do regime de metas para inflação, resultantes do Decreto n. 3088, de 21 de junho de 1999, assinado pelo então presidente da República, Fernando Henrique Cardoso, podem ser classificadas da seguinte forma:

\section{Medidas de transparência política}

_ as metas de inflação serão estabelecidas com base na variação de um índice de preço bastante conhecido;

_ as metas de inflação, assim como os intervalos para flutuação, serão definidos pelo Conselho Monetário Nacional com base em uma proposta do ministro da Fazenda; _ as metas para os anos 1999, $2000 \mathrm{e}$ 2001 serão definidas até 30 de ju- 
nho; para o ano 2002 e anos subseqüentes, até 30 de junho com dois anos de antecedência;

_ ao BCB é dada a responsabilidade para implementar as políticas necessárias para a obtenção das metas;

_ o índice de preços que será adotado para os propósitos do regime de metas para inflação será definido pelo Conselho Monetário Nacional com base na proposta do ministro da Fazenda;

_ as metas serão consideradas levando-se em conta a inflação acumulada no período de janeiro a dezembro de cada ano (medida pelo índice de preços adotado para esse propósito), de forma que se situem dentro do intervalo de tolerância.

\section{Medidas de transparência de política,}

\section{de procedimento e operacional}

_ no caso de as metas não serem alcançadas, o presidente do BCB emitirá uma carta aberta endereçada ao ministro da Fazenda, explicando as causas do descumprimento, as medidas a ser adotadas para garantir que a inflação retorne para os intervalos de tolerância, e o período de tempo que será necessário para que as medidas tenham efeito;

_ o BCB emitirá um relatório de inflação trimestral que informará o desempenho do regime de metas para inflação, os resultados das ações da política monetária, e as perspectivas em relação à inflação.

Apesar de as observações acima mostrarem clara preocupação do BCB de aumentar a transparência, verifica-se que ainda há espaço para que ela possa ser incrementada. Por exemplo, em relação à transparência econômica, percebe-se que o BCB mostra-se muito relutante em divulgar os dados e os modelos utilizados para obter as previsões de inflação ou em divulgar a votação de cada membro do Comitê de Política Monetária (tal como faz o Banco da Inglaterra).

\section{6_Considerações finais}

Dado que o regime de metas para a inflação tem sido adotado por diversos países, e o principal objetivo dessa estrutura é servir como guia para as expectativas inflacionárias dos agentes econômicos, a transparência na condução da política monetária tornou-se uma exigência para o bom funcionamento desse regime monetário. Não obstante, a necessidade de um 
aumento da transparência não é entendida como uma panacéia entre os responsáveis pela condução da política monetária.

Um bom exemplo sobre a importância da transparência na percepção de responsáveis pela condução da política monetária pode ser extraído da XXVI Conferência Anual de Política Econômica do Federal Reserve Bank de St. Louis, realizado no ano de 2002. Charles Freedman - representante do Banco do Canadá salienta que a estabilidade de preços é um meio para um fim, não o objetivo em si mesmo. De acordo com essa perspectiva, a transparência seria importante porque apresenta três vantagens potenciais que contribuiriam para menor volatilidade da taxa de juros e do câmbio:

i. aumenta a comunicação entre os responsáveis pela condução da política econômica;

ii. serve como suporte para a busca de uma meta de baixa inflação;

iii. ajuda a estabilizar o funcionamento do mercado financeiro.

Apesar disso, Václav Klaus - representante da República Tcheca - adverte que a transparência não é a variável-chave para a política monetária. Sob esse ponto de vista, o fundamental é a qualidade do regime monetário e a forma como a política monetária reflete as preferências da sociedade. ${ }^{21}$
Um dos principais motivos para a busca da transparência na condução da política monetária consiste no fato de os gestores de política procurarem reduzir a incerteza que eles mesmos criam. Um aspecto importante é que maior transparência implica que o mercado responde às informações prestadas pelo Banco Central e não à figura política da autoridade monetária. É importante salientar que a definição de transparência está associada com a informação de que os agentes possuem, e não com o simples fato de divulgar informação. A divulgação de informações pode levar a erros de interpretação, contribuindo para o aumento da volatilidade do mercado financeiro. Além disso, se houver a necessidade de os agentes econômicos se esforçarem para extrair alguma informação útil dos dados disponibilizados pelo Banco Central, a informação assimétrica pode perdurar.

Na verdade, uma boa condução da política monetária demanda que o Banco Central tome decisões corretas ante a novas informações. Para tanto, não é necessário que a autoridade monetária tenha um conjunto de funções de reação ex ante que indique como ela reagirá para cada eventualidade. Em suma, a transparência deve ser entendida como um mecanismo que, se utilizado de forma correta, pode contribuir para aumentar a credibilidade na condução da política monetária.

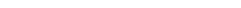

21 Na visão de Klaus, não caberia ao Banco Central decidir qual deveria ser o objetivo de política econômica, mas apenas a escolha do instrumento de política a ser adotado para a consecução de uma meta definida pelo governo. Em outras palavras, a independência do Banco Central deveria estar limitada ao aspecto operacional. 


\section{Referências bibliográficas}

ANDERSSON, K.; BERG, C. The inflation target in Sweden. In: HALDANE, A. G. (Ed.). Targeting inflation. Bank of England, 1995. p. 207-225.

BACKUS, D.; DRIFFILL, J. Inflation and reputation.

American Economic Review, v. 75, n. 3, p. 530-535, 1985.

BARRO, R. J. Recent developments in the theory of rules versus discretion. The Economic Journal, v. 96, p. 23-37, 1986.

BARRO, R. J.; GORDON, D. Rules, discretion and reputation in a model of monetary policy. Journal of Monetary Economics, North-Holland, n. 12, p. 101-121, 1983.

BERNANKE, B. S. The logic of monetary policy. Before the National Economists Club, Washington, D.C., Federal Reserve Board, Dec. 22004.

BERNANKE, B. S.; REINHART, V.; SACK, B.

Monetary policy alternatives at the zero bound: an empirical assessment. Board of Governors of the Federal Reserve, Finance and Economics Discussion Series, p. 2004-2048, Sept. 2004.
BOGDANSKI, J.; TOMBINI, A.; WERLANG, S. Implementing inflation targeting in Brazil. In: Inflation targeting in Brazil: a collection of working papers. Banco Central do Brasil, p. 7-28, 2001.

BRUNILLA, A.; LAHDENPERÄ, H.

Inflation-targets: principal issues and practical implementation. In: HALDANE, A. G. (Ed.). Targeting inflation. Bank of England, 1995. p. 119-134.

CECCHETTI, S. G.; KRAUSE, S. Central Bank structure, policy efficiency, and macroeconomic performance: exploring empirical relationships. Review, Federal Reserve Bank of St. Louis, p. 47-59, July-Aug. 2002.

CHORTAREAS, G; STAVAGE, D.; STERNE, G. Does it pay to be transparent? International evidence from Central Bank forecasts. Review, Federal Reserve Bank of St. Louis, v. 84, n. 4 , p. 99-118, July-Aug. 2002.

\section{CUKIERMAN, A. Are} contemporary Central Banks transparent about economic models and objectives and what difference does it make? Review, Federal Reserve Bank of St. Louis, v. 84, n. 4, p. 15-35, 2002.
CUKIERMAN, A. Establishing a reputation for dependability by means of inflation targets. In: MAHADEVA, Lavan; STERNE, Gabriel. (Eds.). Monetary frameworks in a global context. London: Routledge, 2000.

FAUST, J.; SVENSSON, L. E. O. Transparency and credibility: monetary policy with unobservable goals. International Economic Review, v. 42, n. 2, p. 369-397, 2001

FISCHER, S. Central Bank independence revisited. American Economic Review, v. 85, n. 2, p. 201-206, May 1995.

FRACASSO, A.; GENBERG, H.; WYPLOSZ, C. How do Central Banks write? Geneva special report on the world economy S2, Geneva: International Center for Monetary and Banking Studies, 2003.

FRY, M.; JULIUS, D.;

MAHADEVA, L.; ROGER, S.; STERNE, G. Key issues in the choice of monetary policy framework. In: MAHADEVA, Lavan; STERNE, Gabriel. (Eds.). Monetary policy frameworks in a global context. London: Routledge, 2000. p. 1-216.
GERAATS, P. M. Central Bank transparency. Economic Journal, v. 112, p. 532-565, Nov. 2002.

GERAATS, P. M. Why adopt transparency? The publication of Central Bank forecasts. European Central Bank, 2001. (Working Paper, n. 41).

HERON, E. L. A new consensus on monetary policy? Revista de Economia Politica, v. 23, n. 4 (92), p. 3-27, out./dez. 2003.

HERRENDORF, B. Inflation targeting as a way of precommitment. Oxford Economic Papers. v. 50, n. 3, p. 431-448, July 1998.

IMF. Brazil - Selected Issues and Statistical Appendix. International Monetary Fund, July, 16 ${ }^{\text {th }}, 1999$.

IMF. Code of good practices on transparency in monetary and financial policies: declaration and principles. Disponível em:

<http://www.imf.org/external/ $\mathrm{np} / \mathrm{mae} / \mathrm{mft} /$ code/index.htm $>$.

JENSEN, H. E. Optimal degrees of transparency in European Union countries. Working Paper, University of Copenhagen, 2000. 
KEYNES, J. M. The collect writings of Jobn Maynard Keynes. (Ed.). MOGGREIDGE, Donald. v. 20. Cambridge: Macmillan Press, 1973.

KYDLAND, F. E.; PRESCOTT, E. C. Rules rather than discretion the inconsistency of optimal plans. Journal of Political Economic, v. 85 , n. 3, p. 473-492, 1977

\section{LOHMAN, S. Optimal}

commitment in monetary policy: credibility versus flexibility. American Economic Review, n. 82, p. 273-286, 1992.

McCALLUM, B. International monetary economics. New York: Oxford University Press, 1996.

MISHKIN, F. Can Central Bank transparency go too far? NBER Working Paper 10829, Oct. 2004.

MISHKIN, F. International experiences with differen monetary policy regimes. NBER Working Paper 6965, Feb. 1999.

MISHKIN, F.; POSEN, A. Inflation targeting: lessons from four countries. Economic Policy Review, Federal Reserve Bank of New York, v. 3, n. 3, p. 9-110, Aug. 1997.

MISHKIN, F.;

SCHMIDT-HEBBEL, K. One decade of inflation targeting in the world: what do we know and what do we need to know? NBER Working Paper, 8397, July 2001.
ROGOFF, K. The optimal degree of commitment to an intermediate monetary target. The Quarterly Journal of Economics, p. 1169-1189, Nov. 1985.

\section{SANTOMERO, A. M.}

Flexible commitment or inflation targeting for the U.S.? Business Review, Federal Reserve Bank of Philadelphia, Third Quarter, p. 1-7, 2003.

SVENSSON, L. E. O. Monetary policy and learning. Economic Review, Federal Reserve Bank of Atlanta, Third Quarter, v. 88, n. 3, p. 11-16, 2003

SVENSSON, L. E. Monetary policy issues for the Eurosystem. NBER Working Paper 7177, June 1999.

SVENSSON, L. E. Optimal inflation targets, conservative Central Banks, and linear inflation contracts. American Economic Review, v. 87, n. 1, p. 98-114, 1997.

\section{TAYLOR, J. B. Discretion} versus policy rules in practice. Carnegie-Rochester Conference Series on Public Policy, n. $39,1993$.

WALSH, C. Accountability, transparency, and inflation targeting. Journal of Money, Credit, and Banking, v. 35, n. 5, p. 829-849, Oct. 2003.

WALSH, C. Optimal contracts for Central Bankers. American Economic Review, v. 85, n. 1, p. 150-167, Mar. 1995
- Agradeço os profícuos

- comentários realizados por um

- parecerista anônimo desta

revista, contudo, as possiveis

: omissões ou imprecisões são de

- minha inteira responsabilidade.

E-mail de contato do autor:

: helderfm@hotmail.com 